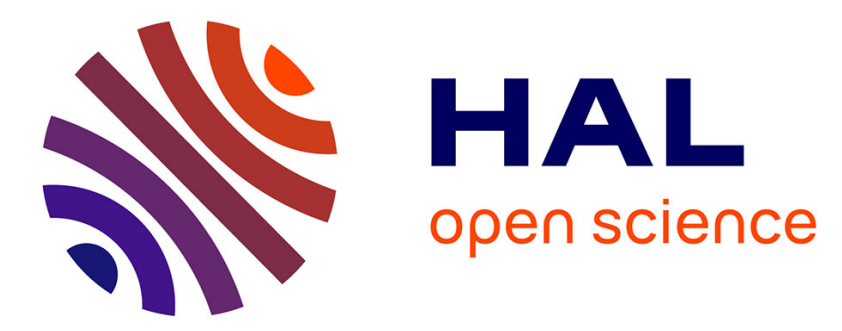

\title{
From thorium phosphate hydrogenphosphate hydrate to $\beta$-thorium phosphate diphosphate: Structural evolution to a radwaste storage ceramic
}

\author{
G. Wallez, Nicolas Clavier, N. Dacheux, M. Quarton, W. van Beek
}

\section{- To cite this version:}

G. Wallez, Nicolas Clavier, N. Dacheux, M. Quarton, W. van Beek. From thorium phosphate hydrogenphosphate hydrate to $\beta$-thorium phosphate diphosphate: Structural evolution to a radwaste storage ceramic. Journal of Solid State Chemistry, 2006, 179, pp.3007-3016. 10.1016/j.jssc.2006.05.027 . in2p3-00106759

\author{
HAL Id: in2p3-00106759 \\ https://hal.in2p3.fr/in2p3-00106759
}

Submitted on 16 Oct 2006

HAL is a multi-disciplinary open access archive for the deposit and dissemination of scientific research documents, whether they are published or not. The documents may come from teaching and research institutions in France or abroad, or from public or private research centers.
L'archive ouverte pluridisciplinaire HAL, est destinée au dépôt et à la diffusion de documents scientifiques de niveau recherche, publiés ou non, émanant des établissements d'enseignement et de recherche français ou étrangers, des laboratoires publics ou privés. 


\section{From thorium phosphate hydrogenphosphate hydrate to $\beta$ - thorium phosphate diphosphate: structural evolution to a radwaste storage ceramic}

Gilles Wallez, ${ }^{a *}$ Nicolas Clavier ${ }^{b}$, Nicolas Dacheux ${ }^{b}$, Michel Quarton, ${ }^{a}$ Wouter van Beek $^{\mathrm{c}}$

${ }^{a}$ Université Pierre et Marie Curie-Paris6, CNRS UMR 7574, Chimie de la Matière Condensée de Paris, 4 place Jussieu, Paris, F-75005 France

${ }^{\mathrm{b}}$ Groupe de Radiochimie, IPN, Université Paris Sud, BP Nº 1, Orsay, F-91406 France

${ }^{\mathrm{c}}$ European Synchrotron Radiation Facility, 6 rue Jules Horowitz, BP 220, Grenoble, F-38043 France

gw@ccr.jussieu.fr

tel. $33-1-44-27-55-32$

fax. $33-1-44-27-25-48$ 


\begin{abstract}
$\beta$-thorium phosphate diphosphate ( $\beta$-TPD), considered as a very promising radwaste storage material, was obtained from thorium phosphate hydrogenphosphate hydrate (TPHPH) precursor through dehydration and phosphate condensation. The structures of TPHPH, intermediate $\alpha$-thorium phosphate diphosphate $(\alpha-$ TPD) and its hydrate $(\alpha-\mathrm{TPDH})$ have been resolved ab initio by Rietveld analysis of their synchrotron diffraction patterns. All are orthorhombic (space group $\mathrm{Cmcm}$ ) and similarly composed of $\left[\mathrm{ThPO}_{4}\right]_{4}{ }^{4+}$ slabs alternating with disordered layers hosting either $\left[\mathrm{HPO}_{4} \cdot \mathrm{H}_{2} \mathrm{O}_{2}{ }^{4-}(\mathrm{TPHPH})\right.$, $\left[\mathrm{P}_{2} \mathrm{O}_{7} \cdot 2 \mathrm{H}_{2} \mathrm{O}\right]^{4-}(\alpha-\mathrm{TPDH})$, or $\left[\mathrm{P}_{2} \mathrm{O}_{7}\right]^{4-}(\alpha-\mathrm{TPD})$, unlike the 3D structure of $\beta$-TPD. The diphosphate groups of $\alpha$-TPD and $\alpha$-TPDH are strongly bent. The irreversible transition to the final $\beta$-TPD consists in a shearing of the slabs and a reduction of the interslabs cavities that explains the stability of this hightemperature form.
\end{abstract}

Keywords: Actinides; Radwaste storage; Synchrotron diffraction; Inorganic structures; Phosphates 


\section{Introduction}

Since the mid-90's, a considerable deal of studies have been dedicated to the search of host matrices for actinides, in the scope of immobilizing high-activity long-life radwastes such as radionuclides coming from an advanced reprocessing of the spent fuel, or excess plutonium from dismantled nuclear weapons. In this scope, the French national research group NOMADE has initiated a multidisciplinary evalution program that allowed to select some host ceramics and composites for their high chemical durability, low aqueous solubility and resistance to radiation damages [1]. Among them, $\mathrm{Th}_{4}\left(\mathrm{PO}_{4}\right)_{4} \mathrm{P}_{2} \mathrm{O}_{7}$ (TPD) shows excellent performances and the possibility to substitute the big $\mathrm{Th}^{\mathrm{IV}}$ cation by smaller ones like $\mathrm{U}^{\mathrm{IV}}, \mathrm{Np}^{\mathrm{IV}}, \mathrm{Pu}^{\mathrm{IV}}$ in large amounts (respectively, up to 75, 52, $41 \mathrm{~mol} \%$ ) [2-5]. This material, considered as promising, can be prepared either by wet or dry chemical route, but the former appears as the most convenient for the elaboration of solid solutions containing both thorium and other actinides, because it allows a more homogeneous distribution of the cations [6,7]. Another strong point of the wet route lies in the very low solubility of the precursor that allows to consider the quantitative decontamination of low- and high-level radioactive liquid waste containing actinides through precipitation [8].

Typically, the precipitation in close container of a stoïchiometric mixture of concentrated $\mathrm{ThCl}_{4}$ solution with $5 \mathrm{M} \mathrm{H}_{3} \mathrm{PO}_{4}$ yields to the crystallized precursor (thorium phosphate hydrogenphosphate hydrate, $\mathrm{Th}_{4}\left(\mathrm{PO}_{4}\right)_{4}\left(\mathrm{HPO}_{4}\right)_{2} 2 \mathrm{H}_{2} \mathrm{O}$ or TPHPH$)$, which is then heated to $1050-1250{ }^{\circ} \mathrm{C}$. Recently, we reported a combined study of the thermal evolution of TPHPH by high-temperature XRD, NMR, EPMA, TGA/DSC, IR and Raman spectroscopy [9], showing several phase transitions (Figure 1):

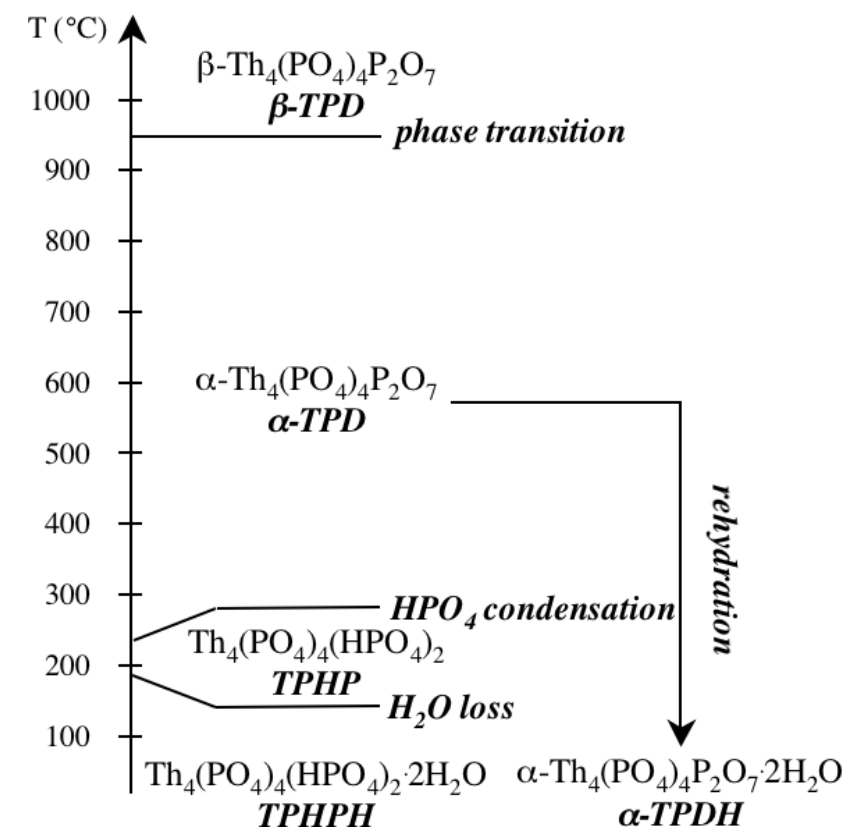

Fig. 1. Thermal evolution scheme for PTHTH. 
- TPHPH dehydrates reversibly around $180^{\circ} \mathrm{C}$ to TPHP (anhydrous thorium phosphate hydrogenphosphate, $\left.\mathrm{Th}_{4}\left(\mathrm{PO}_{4}\right)_{4}\left(\mathrm{HPO}_{4}\right)_{2}\right)$;

- short above $\left(230^{\circ} \mathrm{C}\right)$, the hydrogenphosphate groups of TPHP condense irreversibly into diphosphates, leading to $\alpha$-TPD ( $\alpha$-thorium phosphate diphosphate, $\mathrm{Th}_{4}\left(\mathrm{PO}_{4}\right)_{4} \mathrm{P}_{2} \mathrm{O}_{7}$ );

- left in air at room temperature, $\alpha$-TPD re-hydrates promptly into $\alpha$-TPDH ( $\alpha$-thorium phosphate diphosphate hydrate, $\left.\mathrm{Th}_{4}\left(\mathrm{PO}_{4}\right)_{4} \mathrm{P}_{2} \mathrm{O}_{7} \cdot n \mathrm{H}_{2} \mathrm{O}\right)$;

- around $950{ }^{\circ} \mathrm{C}, \alpha$-TPD transforms irreversibly into $\beta$-TPD ( $\beta$-thorium phosphate diphosphate, $\left.\mathrm{Th}_{4}\left(\mathrm{PO}_{4}\right)_{4} \mathrm{P}_{2} \mathrm{O}_{7}\right)$, also known as TPD in the technical literature. This ultimate form of the host matrix is very stable and immune from re-hydratation. Its crystal structure, resolved as soon as 1996, is orthorhombic Pcam with cell parameters $a=12.8646(9) \AA, \quad b=10.4374(8) \AA, \quad c=7.0676(5) \AA$ $\left(V=949.0(1) \AA^{3}, Z=2\right)$ [10]. No natural analogue is known.

The crystal structures of the other compounds are unpublished, except for a rough model for TPHPH recently proposed by Salvado et al. [11], that will be discussed thereafter. High-temperature XRD has shown a strong similarity between TPHPH, TPHP, $\alpha$-TPD and $\alpha$-TPDH, but except for the closeness of the $c$-cell parameters, neither their patterns nor their cells (orthorhombic $C$, typically $a=21.4 \AA, b=6.7 \AA, c=7.0 \AA, V=1005 \AA^{3}$ ) show clear relations with those of $\beta$-TPD [9]. Another unexplained difference of considerable importance regarding the applications lied in the textures of these materials: whereas TPHPH is soft and foliated, ${ }^{9} \beta$-TPD can be sintered as a ceramic. Likewise, the stability of the $\beta$-form, suggested by the irreversibility of the $\alpha-\beta$ transition, had to be duly established. So, although being of a considerable interest, the wet route remained obscure by many points, urging us to elucidate of the crystal structures of TPHPH, $\alpha$-TPD and $\alpha$-TPDH. Note that TPHP was excluded from this study because of the closeness and the spreading of the TPHPH/TPHP and TPHP/ $\alpha$-TPD transitions that do not allow to prepare this intermediate form pure enough.

\section{Experimental Section}

The TPHPH sample used as starting material for these studies was synthesized following the wet route described above. ${ }^{6,7}$ It was studied by powder diffraction and Electron Probe MicroAnalysis 
(EPMA) using $\mathrm{SmPO}_{4}$ and $\mathrm{ThO}_{2}$ as calibration standards, as already described [9]. In neither case did impurities appear.

\section{Thermogravimetric analysis}

In a preliminary study, cyclic DTA/TGA's of $\alpha$-TPDH were performed in order to measure the number of water molecules in this compound. The experiments, made in air on a Setaram TG 92-16 apparatus with a $120{ }^{\circ} \mathrm{C} \cdot \mathrm{h}^{-1}$ heating/cooling rate, evidenced two phenomena (Figure 2):

- a diffuse mass loss starting from $50{ }^{\circ} \mathrm{C}$ on heating, reaching 1.1 to $1.9 \%$ depending on the sample, that can be attributed to adsorbed water; the reverse phenomenon was not observed, probably because of a slow kinetics;

- although the two losses overlap each other, the second one appears sharper and fully reversible during cooling and subsequent cycles, therefore, it can be quantified. This $2.3 \%$ loss, also pointed out by DTA, occurs between 190 and $300{ }^{\circ} \mathrm{C}$. It corresponds to two water molecules per $\mathrm{Th}_{4}\left(\mathrm{PO}_{4}\right)_{4} \mathrm{P}_{2} \mathrm{O}_{7}$ unit $(2.37 \%$ in theory), so leading to assign $\mathrm{Th}_{4}\left(\mathrm{PO}_{4}\right)_{4} \mathrm{P}_{2} \mathrm{O}_{7} \cdot 2 \mathrm{H}_{2} \mathrm{O}$ as the probable formula for the hydrated $\alpha$-TPDH compound. When cooling, the compound rehydrates from $260{ }^{\circ} \mathrm{C}$ on, accounting for strongly bonded structural water molecules.

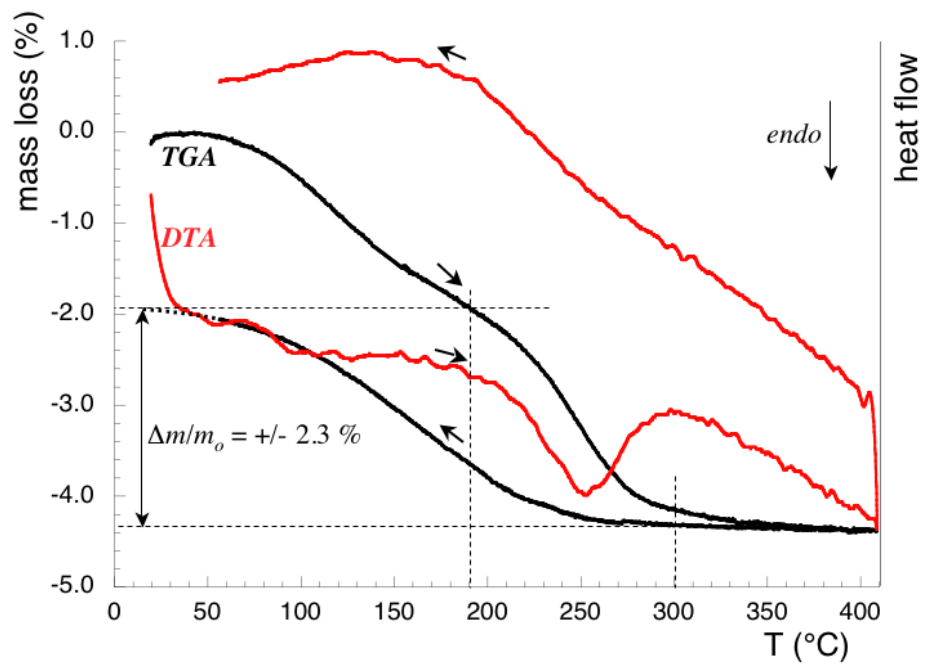

Fig. 2. DTA/TGA plot for $\alpha-T P D H$.

\section{Synchrotron Diffraction}


Because single-crystals of these compounds have never been obtained (except for the final $\beta$ $\mathrm{TPD}^{10}$ ), the following studies have been carried out on powders. TPHPH and $\alpha$-TPDH have been introduced into $0.3 \mathrm{~mm}$ glass capillaries. $\alpha$-TPD, very prone to re-hydration, was directly prepared in its capillary from a second $\alpha$-TPDH sample heated for 2 hours at $400{ }^{\circ} \mathrm{C}$, then immediately sealed. After recording on the BM01B line of the European Synchrotron Radiation Facility (Grenoble, France), the diffracted intensities were combined into $0.006^{\circ}$ bins for Rietveld analysis. Figure 3 shows the Rietveld plot for TPHPH. Operating and analysis conditions are reported in Table 1.

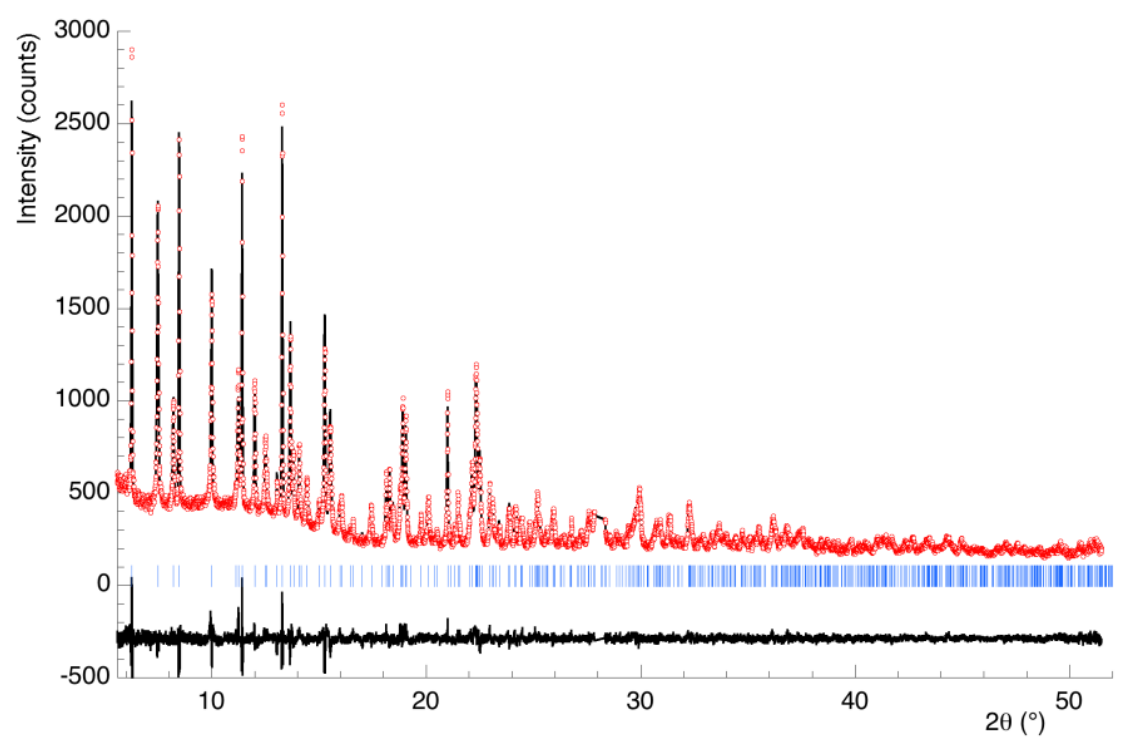

Fig. 3. Rietveld plot for TPHPH: $I_{o b s}$ (circles), $I_{c a l}$ (solid), Bragg positions (bars) and $I_{o b s}-I_{c a l}$ (solid, lower).

Table 1

Data collection, refinement conditions and crystallographic data for TPHPH, $\alpha$-TPD and $\alpha-T P D H$

\begin{tabular}{|c|c|c|c|}
\hline Data collection for & TPHPH & $\alpha$-TPD & $\alpha-\mathrm{TPDH}$ \\
\hline Temperature & $293 \mathrm{~K}$ & & \\
\hline Apparatus & ESRF-BM01B & & \\
\hline $\begin{array}{l}\text { Wavelength, } \\
\text { monochromator }\end{array}$ & $\begin{array}{l}0.69947 \AA \\
\text { (111) Si (rear) }\end{array}$ & $\begin{array}{l}0.50007 \AA \\
\text { (111) Si (rear) }\end{array}$ & $\begin{array}{l}0.69947 \AA \\
\text { (111) Si (rear) }\end{array}$ \\
\hline $2 \theta$ scan limits, step & $4.06-55.50^{\circ}, 0.006^{\circ}$ & $5.56-45.50^{\circ}, 0.006^{\circ}$ & $4.06-51.50^{\circ}, 0.006^{\circ}$ \\
\hline Observed reflections & 725 & 1133 & 598 \\
\hline
\end{tabular}




\begin{tabular}{|l|l|l|l|}
\hline Refinement conditions for & TPHPH & $\alpha$-TPD & $\alpha$-TPDH \\
\hline I-dependent parameters & 37 & 32 & 35 \\
\hline Background fitting & \multicolumn{3}{|l|}{ interpolation between selected points } \\
\hline Profile model & \multicolumn{2}{|l|}{ Thompson-Cox-Hastings with anisotropic size effect } \\
\hline$R_{P}=\Sigma \mid y_{o}{ }^{i}-\mathrm{y}_{\mathrm{c}}{ }^{\mathrm{i}} / / y_{\mathrm{o}}{ }^{\mathrm{i}}$ & 0.038 & 0.042 & 0.036 \\
$R_{W P}(\mathrm{id} .$, weighted $)$ & 0.049 & 0.055 & 0.045 \\
$R_{\text {Bragg }}=\Sigma \mid I_{o}{ }^{i}-I_{c}{ }^{i} / / \Sigma I_{o}$ & 0.039 & 0.032 & 0.027 \\
$R_{\text {exp }}=\left((n-p) / \Sigma w_{i} y_{\mathrm{o}}{ }^{i}\right)^{1 / 2}$ & 0.027 & 0.042 & 0.039 \\
$R_{F}=\Sigma\left|\left(I_{o}{ }^{1}\right)^{1 / 2}-\left(I_{c}{ }^{i}\right)^{1 / 2}\right| / \Sigma\left(I_{o}{ }^{i}\right)^{1 / 2}$ & 0.032 & 0.020 & 0.019 \\
$\chi^{2}=\left(R_{W P} / R_{\text {exp }}\right)^{2}$ & 1.4 & 1.7 & 1.4 \\
\hline
\end{tabular}

\begin{tabular}{|l|l|l|l|}
\hline Crystallographic data for & TPHPH & $\alpha$-TPD & $\alpha$-TPDH \\
\hline Formula & $\mathrm{Th}_{4}\left(\mathrm{PO}_{4}\right)_{4}\left(\mathrm{HPO}_{4}\right)_{2} 2 \mathrm{H}_{2} \mathrm{O}$ & $\mathrm{Th}_{4}\left(\mathrm{PO}_{4}\right)_{4}\left(\mathrm{P}_{2} \mathrm{O}_{7}\right)$ & $\mathrm{Th}_{4}\left(\mathrm{PO}_{4}\right)_{4}\left(\mathrm{P}_{2} \mathrm{O}_{7}\right) 2 \mathrm{H}_{2} \mathrm{O}$ \\
\hline System, space group & Orthorhombic, Cmcm (63) & \\
\hline$a(\AA)$ & $21.4201(2)$ & $21.4205(2)$ & $6.69080(5)$ \\
$b(\AA)$ & $6.69826(5)$ & $6.69180(4)$ & $7.02710(5)$ \\
$c(\AA)$ & $7.03348(4)$ & $7.02925(4)$ & $1006.95(2)$ \\
$V\left(\AA^{3}\right)$ & $1009.14(2)$ & $1007.59(2)$ & $2,1518,5.01$ \\
\hline$Z$, formula weight $\left(\mathrm{g} . \mathrm{mol}^{-1}\right)$, & $2,1536,5.06$ & $2,1481,4.88$ & \\
calc. density & & & \\
\hline
\end{tabular}

Using instrumental parameters refined previously from a $\mathrm{LaB}_{6}$ pattern, the Rietveld analysis in profile-matching mode, performed with Fullprof.2k [12] confirmed the orthorhombic cells already reported [9]. The intensities were extracted and corrected from absorption, considering a $20 \%$ compactness as measured by weighting the capillaries.

The platelet habit of the crystallites [9] generated a broadening of the $h$-dependent peaks and a slight orientation effect on the intensities that were taken into account. Systematic extinctions showed a $C$-lattice and a $c$-glide mirror perpendicular to $\boldsymbol{b}$. The pycnometric measurements [9] accounted for two $\mathrm{Th}_{4}\left(\mathrm{PO}_{4}\right)_{4}\left(\mathrm{HPO}_{4}\right)_{2} 2 \mathrm{H}_{2} \mathrm{O}$ (or equivalent) formulae per cell.

A Patterson synthesis performed with SHELX-97 [13] allowed to locate the thorium atoms. The analysis of the Fourier maps [14] of the three compounds revealed dense $\left[\mathrm{Th}_{4}\left(\mathrm{PO}_{4}\right)_{4}\right]^{4+}$ slabs extending parallel to the $(\boldsymbol{b}, \boldsymbol{c})$ plane. At this point, we remarked that these atoms, as well as the residual electron 
density, obeyed to $m$-mirrors perpendicular to $\boldsymbol{a}$ and $\boldsymbol{c}$, the Th, $\mathrm{P}(1)$ and some $\mathrm{O}$ atoms being located on the second one. For instance, an attempt of refinement in the $C c$ space group yielded in differenciated positions of Th atoms only 0.03(1) $\AA$ apart from their sites in $\mathrm{Cmcm}$ and complying with the (001) $\mathrm{m}$ mirror $(\Delta z=0.003(6))$, thus leading to adopt the latter space group.

\section{Results}

As could be inferred from their powder patterns, the three compounds show a remarkable similarity in the structure of their $\left[\mathrm{Th}_{4}\left(\mathrm{PO}_{4}\right)_{4}\right]^{4+}$ slabs. The thorium atom is bonded to six oxygen atoms of the $\mathrm{P}(1) \mathrm{O}_{4}$ groups, forming an hemispheric polyhedron. The close packing of $\mathrm{Th}$ and $\mathrm{P}(1) \mathrm{O}_{4}$ in the slabs differs from the monazite type by the orientation of the tetrahedra, which share two edges with the other anionic polyhedra in the latter and only one in the title compounds. Note that this edge is short, with a correlatively low $\mathrm{O}(11)-\mathrm{P}(1)-\mathrm{O}(11)$ angle $\left(96.3(5)^{\circ}\right.$ for TPHPH).

On the Fourier maps, the 4 other phosphate groups in the cell (and the water molecules if any) appear scattered in the interslabs over equivalent $16 \mathrm{~h}$ (general) positions of $\mathrm{Cmcm}$, supposing a 1/4 occupancy rate. The case of each compound will be detailed below, the atomic coordinates are reported in Table 2.

Table 2

Atomic coordinates and isotropic displacement factors for TPHPH, $\alpha$-TPD and $\alpha$-TPDH (in this order)

\begin{tabular}{|c|c|c|c|c|c|}
\hline Atom & $x$ & $y$ & $z$ & site, occ. & $\begin{array}{c}B_{\text {iso }}{ }^{*}, B_{e q}\left(\AA^{2}\right) \text { for } \\
\text { Th }\end{array}$ \\
\hline \multirow[t]{3}{*}{ Th } & $0.36002(4)$ & $0.6481(1)$ & $1 / 4$ & $8 g, 1$ & $1.40(4)$ \\
\hline & $0.35982(3)$ & $0.64805(9)$ & & & $0.78(2)$ \\
\hline & $0.35974(5)$ & $0.6482(1)$ & & & $0.58(2)$ \\
\hline \multirow[t]{3}{*}{$\mathrm{P}(1)$} & $0.18215(7)$ & $0.6747(3)$ & $1 / 4$ & $8 g, 1$ & $1.3(1)$ \\
\hline & $0.18229(7)$ & $0.6868(2)$ & & & $1.14(8)$ \\
\hline & $0.18279(7)$ & $0.6837(3)$ & & & $0.7(1)$ \\
\hline \multirow[t]{3}{*}{$\mathrm{P}(2)$} & $0.5155(1)$ & $0.6640(8)$ & $0.5236(6)$ & $16 h, 1 / 4$ & \\
\hline & $0.5098(3)$ & $0.6459(8)$ & $0.5463(6)$ & & \\
\hline & $0.5109(3)$ & $0.641(1)$ & $0.5544(8)$ & & \\
\hline
\end{tabular}




\begin{tabular}{|c|c|c|c|c|c|}
\hline \multirow[t]{3}{*}{$\mathrm{O}(11)$} & $0.1597(3)$ & $0.8100(8)$ & $0.0871(6)$ & $16 h, 1$ & $0.5(1)$ \\
\hline & $0.1614(3)$ & $0.8232(8)$ & $0.0857(6)$ & & $0.17(8)$ \\
\hline & $0.1613(4)$ & $0.815(1)$ & $0.0832(7)$ & & $0.1(1)$ \\
\hline \multirow[t]{3}{*}{$\mathrm{O}(12)$} & $0.2539(1)$ & $0.656(2)$ & $1 / 4$ & $8 g, 1$ & \\
\hline & $0.2538(1)$ & $0.661(1)$ & & & \\
\hline & $0.2541(1)$ & $0.654(2)$ & & & \\
\hline \multirow[t]{3}{*}{$\mathrm{O}(13)$} & $0.1475(5)$ & $0.4734(9)$ & $1 / 4$ & $8 g, 1$ & \\
\hline & $0.1485(4)$ & $0.4840(7)$ & & & \\
\hline & $0.1454(6)$ & $0.487(1)$ & & & \\
\hline \multirow[t]{3}{*}{$\mathrm{O}(21)$} & $0.5549(3)$ & $0.483(1)$ & $0.552(2)$ & $16 h, 1 / 4$ & \\
\hline & $0.544(1)$ & $0.455(2)$ & $0.588(3)$ & & \\
\hline & $0.539(1)$ & $0.444(3)$ & $0.611(4)$ & & \\
\hline \multirow[t]{3}{*}{$\mathrm{O}(22)$} & $0.5359(5)$ & $0.790(2)$ & $0.362(2)$ & $16 h, 1 / 4$ & \\
\hline & $0.5379(9)$ & $0.795(3)$ & $0.409(2)$ & & \\
\hline & $0.543(2)$ & $0.760(4)$ & $0.404(4)$ & & \\
\hline \multirow[t]{3}{*}{$\mathrm{O}(23)$} & $0.4472(2)$ & $0.6154(9)$ & $0.511(1)$ & $16 h, 1 / 4$ & \\
\hline & $0.4475(6)$ & $0.582(3)$ & $0.471(4)$ & & \\
\hline & $0.4476(8)$ & $0.578(4)$ & $0.486(5)$ & & \\
\hline $\mathrm{OH}$ & $0.5219(9)$ & $0.800(2)$ & $0.712(2)$ & $16 h, 1 / 4$ & \\
\hline $\mathrm{O}_{\mathrm{b}}$ & $1 / 2$ & $0.753(1)$ & $3 / 4$ & $4 c, 1 / 2$ & \\
\hline $\mathrm{O}_{\mathrm{b}}$ & $1 / 2$ & $0.762(2)$ & $3 / 4$ & $4 c, 1 / 2$ & \\
\hline \multirow[t]{3}{*}{$\mathrm{O}_{\mathrm{w}}$} & $0.4558(2)$ & $0.1999(7)$ & $0.568(2)$ & $16 h, 1 / 4$ & \\
\hline & & - & - & - & \\
\hline & $0.458(1)$ & $0.144(5)$ & $0.594(4)$ & $16 h, 1 / 4$ & \\
\hline
\end{tabular}

* common for $\mathrm{P}(1)$ and $\mathrm{P}(2)$ on the one hand, and for all oxygen atoms on the other hand.

\section{TPHPH}

The $\mathrm{Cmcm}$ space group precludes the interslab species from occupying fully their sites, because the lowest site multiplicity (4) is twice the number of each of these units $\left(2 \mathrm{HPO}_{4}\right.$ and $\left.2 \mathrm{H}_{2} \mathrm{O}\right)$. Indeed, the Fourier maps show electron residuals on $16 h$ sites of the interslabs, with densities corresponding to a 1/4 occupancy (experimentally: $0.253(2)$ ). The ordering of the interslab is very probable because the phosphate sites overlap each other strongly, so that the presence of a unit forbids the occupation of the three nearest sites. The overlaps are also strong between these phosphates and the water molecules, 
leading to a unique array once a phosphate is placed in one of its four possible sites. For the example shown in Figure 4, the non-occupied equivalent positions have been omitted, but they can be deduced through the missing symmetry elements, giving the three other possible arrays. The compactness of this packing results in an order that extends mechanically to the whole $(\boldsymbol{b}, \boldsymbol{c})$ interslabs layer, reducing its symmetry to a mere $c$-glide mirror.

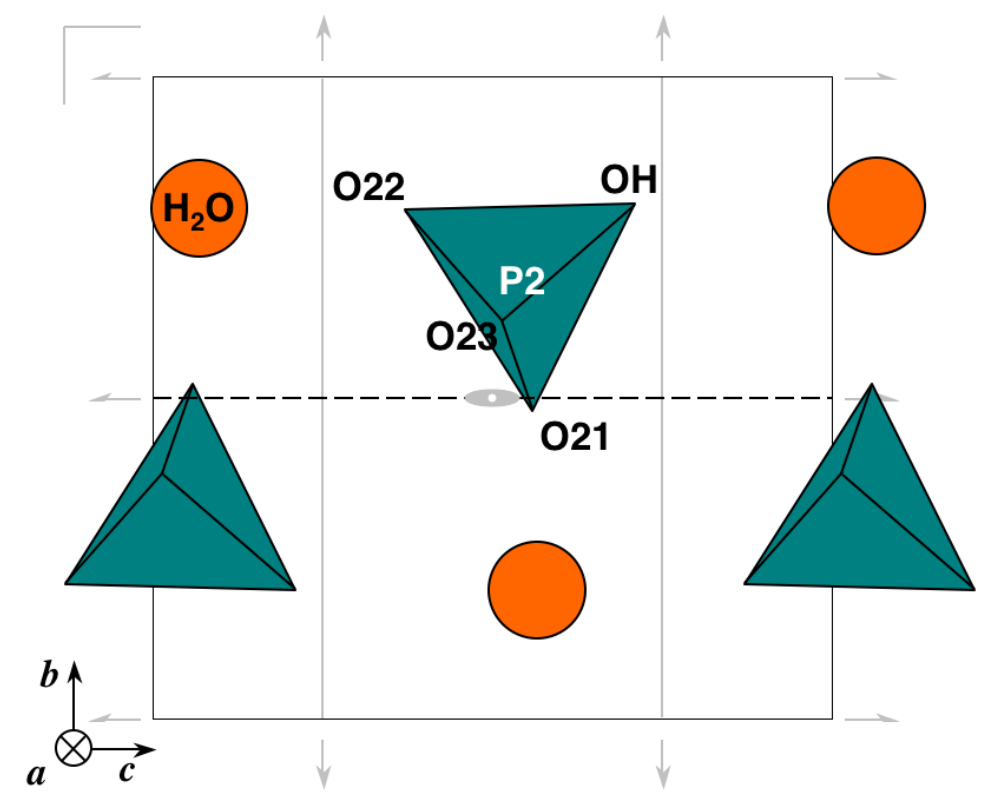

Fig. 4. One of the four possible arrays for the (100) interslab near $x=1 / 2$ in TPHPH, featuring the $c$ glide plane at $y=1 / 2$. Some of the lost symmetry elements of $\mathrm{Cmcm}$ are drawn in grey.

However, it is probable that the thickness of the slabs precludes any ordering interaction following $\boldsymbol{a}$, consistently with the absence of superstructure diffraction peaks, as illustrated on the (010) projection (Figure 5), that features an aperiodic random succession of the interslabs species. The position of one of the interslabs oxygen atoms $(\mathrm{OH})$, far from all thorium atoms $(d>4 \AA)$ confirms that this unit is the hydrogenphosphate. During the refinement, soft constraints were applied on the P-O distances and O-P-O angles of this tetrahedron, taking those of $\mathrm{K}_{2} \mathrm{HPO}_{4}$ as a reference [15]. The water molecule appears surrounded by 7 oxygen (non-water) atoms $\left(2.62 \AA<d \mathrm{O}_{\mathrm{w}}-\mathrm{O}<3.20 \AA\right.$ ), and one thorium atom.

As a consequence of the reduction of symmetry in the interslabs, the unique thorium atom presents paradoxally two kinds of environments, notwithstanding the indirect effect on the neighbor $\mathrm{P}(1) \mathrm{O}_{4}$ tetrahedra: half (thereafter refered as $\mathrm{Th} / \mathrm{A}$ ) are bonded to $\mathrm{O}(23)$ of the $\mathrm{HPO}_{4}$ unit and $\mathrm{O}_{\mathrm{w}}$ of the 
water molecule, the other half $(\mathrm{Th} / \mathrm{B})$ are bonded to $\mathrm{O}(21)$ and $\mathrm{O}(22)$, that is, in both cases, an 8-fold coordination. The ordering of the interslabs imposes that all thorium atoms on the same side of a slab are of the same kind (A or B) and different from those forming the other side of the interslab. However, the disorder following $\boldsymbol{a}$ does not impose any correlation between the opposite sides of a slab.

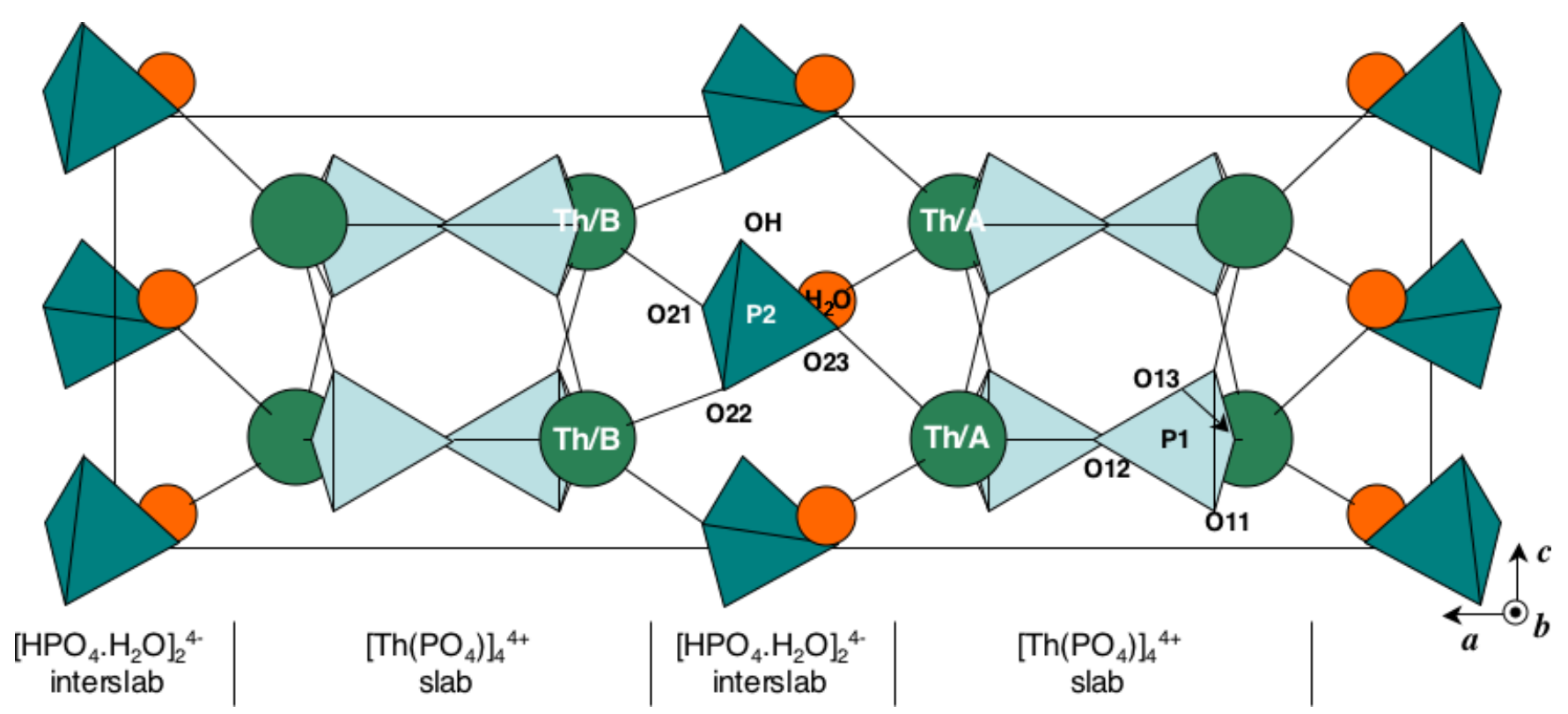

Fig. 5. (010) view of TPHPH. P-O distances $(\AA)$ : $\mathrm{P}(1)-\mathrm{O}(11)=1.538(5)(2 \mathrm{x}),-\mathrm{O}(12)=1.541(3),-\mathrm{O}(13)$ $=1.539(7), \mathrm{P}(2)-\mathrm{O}(21)=1.493(8),-\mathrm{O}(22)=1.48(1),-\mathrm{O}(23)=1.502(5),-\mathrm{OH}=1.61(1)$.

The slight shift we reported above when assuming two independent Th atoms in the $C c$ symmetry may be a consequense of the differenciation, although it seems difficult to correlate each position with the type (A or B) of environment. Indeed, the slab seems rigid enough to remain unsensitive to the drop of symmetry of the interslabs, thus allowing us to consider mean positions for Th and $\mathrm{P}(1) \mathrm{O}_{4}$ in the refinements. It is also worth to note their quasi-invariance from TPHPH to $\alpha$-TPD. The final esd's on Th and P(1) coordinates are low enough to validate this orthorhombic model. Indeed, no subgroup allows to depict correctly the occupation of many interslabs site, as observed on the Fourier maps. For example, extending the $C c$ symmetry to the whole structure by doubling the slab's atoms gives $R_{\text {Bragg }}=0.053$ instead of 0.039 for $\mathrm{Cmcm}$.

The bond strength calculation for Th, using Breese's model [16] (Table 3), shows a nonnegligible contribution of the water molecule ( 0.29 valence units) that allows to fullfil the valence of 
Th/A. More, in the space, the water molecules of TPHPH complete the coordination sphere of half of the thorium atoms and contribute to stabilize this compound.

Table 3

Th-O distances $(\AA)$ in TPHPH, $\alpha$-TPD and $\alpha$-TPDH. Cumulated bond strengths $\left(\Sigma_{0} s_{\mathrm{o}}\right.$ in valence units $)$ are calculated from [16]

\begin{tabular}{|c|c|c|c|c|c|c|}
\hline & \multicolumn{2}{|c|}{ ТPHPH } & \multicolumn{2}{|c|}{$\alpha-T P D$} & \multicolumn{2}{|c|}{$\alpha-\mathrm{TPDH}$} \\
\hline & $\mathrm{Th} / \mathrm{A}$ & $\mathrm{Th} / \mathrm{B}$ & $\mathrm{Th} / \mathrm{A}$ & $\mathrm{Th} / \mathrm{B}$ & $\mathrm{Th} / \mathrm{A}$ & $\mathrm{Th} / \mathrm{B}$ \\
\hline $\mathrm{O}(11)(2 \mathrm{x})$ & \multicolumn{2}{|c|}{$2.573(6)$} & \multicolumn{2}{|c|}{$2.503(5)$} & \multicolumn{2}{|c|}{$2.557(6)$} \\
\hline $\mathrm{O}(11)(2 \mathrm{x})$ & \multicolumn{2}{|c|}{$2.425(5)$} & \multicolumn{2}{|c|}{$2.411(4)$} & \multicolumn{2}{|c|}{$2.397(5)$} \\
\hline $\mathrm{O}(12)$ & \multicolumn{2}{|c|}{$2.275(2)$} & \multicolumn{2}{|c|}{$2.272(2)$} & \multicolumn{2}{|c|}{$2.262(3)$} \\
\hline $\mathrm{O}(13)$ & \multicolumn{2}{|c|}{$2.185(6)$} & \multicolumn{2}{|c|}{$2.254(5)$} & \multicolumn{2}{|c|}{$2.272(7)$} \\
\hline $\mathrm{O}(21)$ & & $2.453(9)$ & $2.45(2)$ & & $2.45(3)$ & \\
\hline $\mathrm{O}(22)$ & & $2.55(1)$ & & $2.65(2)$ & & $2.46(3)$ \\
\hline $\mathrm{O}(23)$ & $2.626(6)$ & & & $2.48(2)$ & & $2.55(3)$ \\
\hline $\mathrm{O}_{\mathrm{w}}$ & $2.625(8)$ & & & & $2.74(3)$ & \\
\hline$\Sigma_{\mathrm{o}} S_{\mathrm{o}}$ & 3.9 & 4.2 & 3.8 & 4.1 & 4.0 & 4.1 \\
\hline
\end{tabular}

The only known isotype of TPHPH is its cerium counterpart, $\mathrm{Ce}_{4}\left(\mathrm{PO}_{4}\right)_{4}\left(\mathrm{HPO}_{4}\right)_{2} 2 \mathrm{H}_{2} \mathrm{O}$ [17], which has similar cell parameters $(a=21.0142(3) \AA, \quad b=6.55082(7) \AA, \quad c=6.94382(6) \AA$, $\left.\beta=91.983(1)^{\circ}, V=955.32(2) \AA^{3}\right)$, but is monoclinic $C 2 / c$, therefore, the atoms ignore the special position on the $m$-mirror at $z=1 / 2$. Its structure is very similar to that of TPHPH, but the lower overall symmetry results in $50 \%$-occupied positions in the interslabs instead of $25 \%$.

The TPHPH cell reported by Salvado et al is monoclinic $P 2_{1}$ (instead of orthorhombic $\mathrm{Cmcm}$ ) [11]. The monoclinic $(m)$ and orthorhombic $(o)$ cells can be linked as follows:

$$
\boldsymbol{a}_{\boldsymbol{m}}=\boldsymbol{b}_{\boldsymbol{o}} ; \boldsymbol{b}_{\boldsymbol{m}}=\boldsymbol{c}_{\boldsymbol{o}} ; \boldsymbol{c}_{\boldsymbol{m}}=\left(\boldsymbol{a}_{\boldsymbol{o}}+\boldsymbol{b}_{\boldsymbol{o}}\right) / 2 ; V_{m}=V_{o} / 2
$$


Based upon an improper cell, this model ignores most of the symmetries, absent in the monoclinic system. Although the slabs of the TPHPH structure show a roughly similar array of $\mathrm{Th}$ and $\mathrm{PO}_{4}$ units, these authors doubled each atom of the assymmetric unit. They also ignored the $m$-mirror perpendicular to $\boldsymbol{c}_{\boldsymbol{o}}\left(\right.$ i.e. $\left.\boldsymbol{b}_{\boldsymbol{m}}\right)$, therefore the special position of Th and $\mathrm{P}(1)$, although theirs lie in the same $(010)_{m}$ plane. The resulting thorium polyhedra have odd open shapes, esd's on the Th-O distances are high and cumulated bond strengthes for the thorium atoms are worth 3.3 and 4.4. The array of the $\mathrm{HPO}_{4}$ and $\mathrm{H}_{2} \mathrm{O}$ units is very different from ours and ignores the disorder. Indeed, our preliminary X-ray studies inclined us to think that, even with the right cell, a structure with such extreme electron densities on atoms sites can hardly be resolved with a mere laboratory X-ray diffractometer.

\section{$\alpha-T P D$}

Two hypotheses are consistent with the existence of only two $\mathrm{P}_{2} \mathrm{O}_{7}$ units in the $C m c m$ cell:

- the two tetrahedra of a diphosphate are equivalent through either a $m$-mirror or a two-fold axis belonging to $\mathrm{Cmcm}$ and located on the bridging oxygen $\mathrm{O}_{\mathrm{b}}$, thus leading to a local $m$ or 2 symmetry (an inversion center can be excluded according to a previous NMR study [18]);

- these tetrahedra are non-equivalent, leading to a 1 symmetry (in this case, all the non-trivial symmetry elements of $\mathrm{Cmcm}$ are lost).

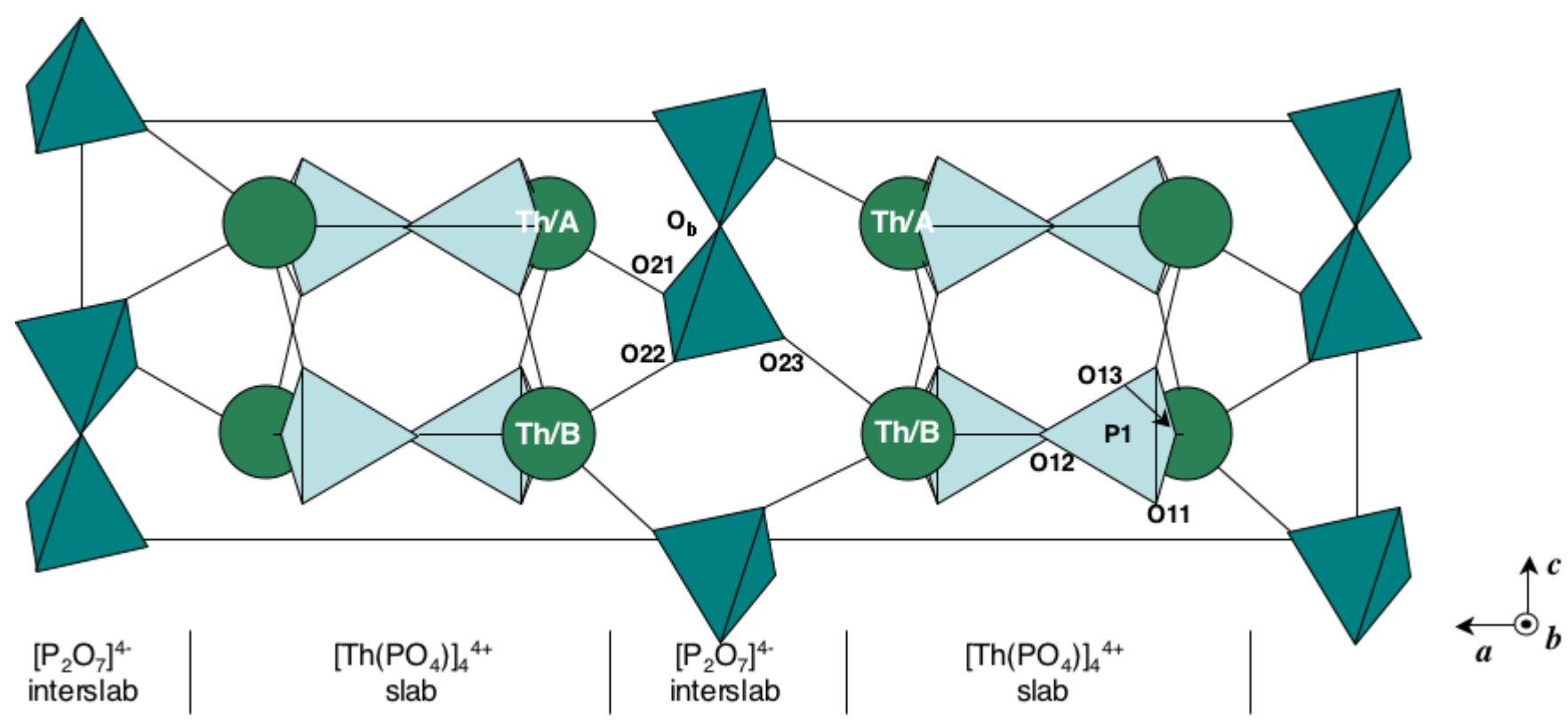

Fig. 6. (010) view of $\alpha$-TPD. P-O distances $(\AA)$ : P(1)-O(11) = 1.538(5) (2x), -O(12) = 1.542(3), -O(13) $=1.539(6), \mathrm{P}(2)-\mathrm{O}(21)=1.50(2),-\mathrm{O}(22)=1.52(2),-\mathrm{O}(23)=1.50(2),-\mathrm{O}_{\mathrm{b}}=1.616(6)$. 
Every possible symmetry reduction has been considered, but for steric reasons, the only realistic solution was to place $\mathrm{O}_{\mathrm{b}}$ on the $\boldsymbol{b}$-directed two-fold axis of $\mathrm{Cmcm}$ (position $4 c$ ). This model also gave the lowest reliability factors. A resolution led with the second model resulted into a similar geometry. For the same steric reasons as for TPHPH, the $\mathrm{P}_{2} \mathrm{O}_{7}$ units of $\alpha$-TPD necessarily order in the $(\boldsymbol{b}, \boldsymbol{c})$ planes (Figure 6), but probably not following the $\boldsymbol{a}$-axis. The interatomic distances appear satisfactory (Table $3)$. Note that the refined value of the interslabs sites occupation factor is close to $1 / 4(0.244(3))$, as for TPHPH, in agreement with the Cmcm symmetry.

The TPHPH/ $\alpha$-TPD transition, requires the inversion of half of the $\mathrm{HPO}_{4}$ tetrahedra, that is, the breaking and reformation of some Th-O bonds in the interslabs. In so doing, half of the Th/A become $\mathrm{Th} / \mathrm{B}$ and reciprocally, so the new order results in an alternation of $\mathrm{Th} / \mathrm{A}$ and $\mathrm{Th} / \mathrm{B}$ atoms on the same side of a slab, at variance with TPHPH.

Th/B keeps the same environment as in TPHPH, but Th/A loses the neighbor water molecule, resulting in an open seven-fold polyhedron, with uncomplete cumulated bond strength for the cation. Soft constraints were applied to the $\mathrm{P}(2)-\mathrm{O}$ distances and O-P(2)-O angles for the refinement. The $\mathrm{P}(2)-$ $\mathrm{O}_{\mathrm{b}}-\mathrm{P}(2)$ (non-constrained) linkage appears strongly bent $\left(127.1(5)^{\circ}\right)$, as usually in diphosphates. In a survey of the vibrational spectroscopy of anhydrous phosphates, Rulmont et al. correlate unambiguously the $\Delta v=\left(v_{\mathrm{as}}-v_{\mathrm{s}}\right)$ and $\Delta=\left(v_{\mathrm{as}}-v_{\mathrm{s}}\right) /\left(v_{\mathrm{as}}+v_{\mathrm{s}}\right)$ parameters derived from the stretching frequencies of 15 diphosphates to the P-O-P angles, in the $124-180^{\circ}$ domain [19]. Once integrated into these plots, the $\Delta v$ and $\Delta$ values calculated from the Raman spectrum of $\alpha$-TPD at $250{ }^{\circ} \mathrm{C}\left(v_{\mathrm{s}}=778 \mathrm{~cm}^{-1}, v_{\mathrm{as}}=940 \mathrm{~cm}^{-1}\right)$ [9], account for a P-O-P angle around $123^{\circ}$. As far as we can rely on the scarce data of this region of the plot, the calculated value appears in good agreement with the result of the Rietveld analysis.

\section{$\alpha-T P D H$}

As in $\alpha$-TPD, the symmetry of the interslabs appears reduced to the $\boldsymbol{b}$-directed two-fold axis of $\mathrm{Cmcm}$. The previous order/disorder considerations apply to this form, resulting in an array similar to that of the anhydrous form, with a water molecule in addition close to its position in TPHPH (Figure 7). The refined value of the $16 h$ interslabs sites occupation factor is $0.244(2)$. 


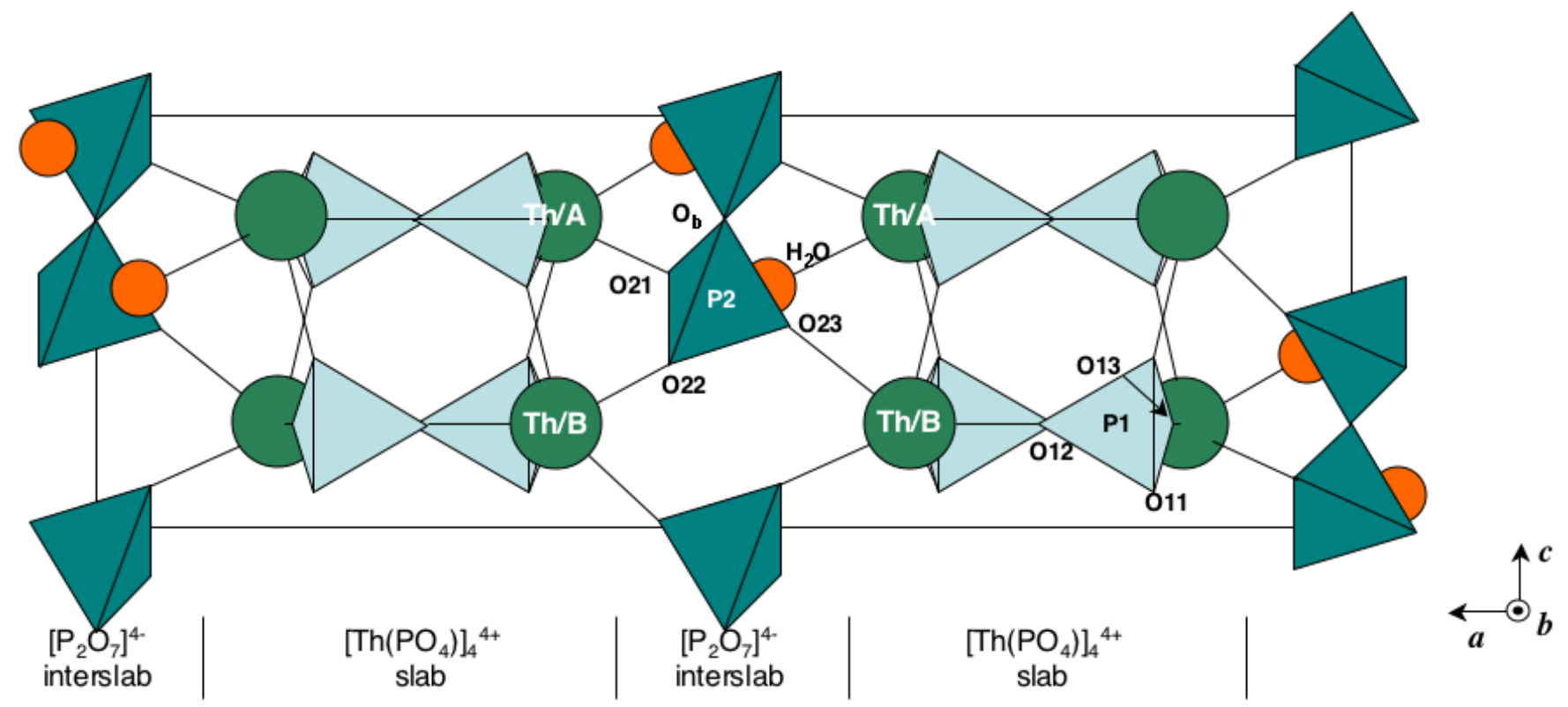

Fig. 7. (010) view of $\alpha$-TPDH. P-O distances $(\AA)$ : $\mathrm{P}(1)-\mathrm{O}(11)=1.537(6)(2 \mathrm{x}),-\mathrm{O}(12)=1.540(4)$, $\mathrm{O}(13)=1.539(9), \mathrm{P}(2)-\mathrm{O}(21)=1.51(2),-\mathrm{O}(22)=1.50(3),-\mathrm{O}(23)=1.50(2),-\mathrm{O}_{\mathrm{b}}=1.613(8)$.

The molecule is surrounded by another water molecule $(2.85(4) \AA), 6$ non-water oxygen atoms $\left(2.61<d \mathrm{O}_{\mathrm{w}}-\mathrm{O}<3.06 \AA\right)$, and one thorium atom. The bending of the $\mathrm{P}(2)-\mathrm{O}_{\mathrm{b}}-\mathrm{P}(2)$ linkage $\left(119.7(6)^{\circ}\right)$ is still stronger than in $\alpha$-TPD, even if this value must be considered with care, because of the low weight of the $\mathrm{P}_{2} \mathrm{O}_{7}$ group in the formula. To our knowledge, a lower angle has been observed only in $\alpha-$ $\mathrm{Na}_{2} \mathrm{CuP}_{2} \mathrm{O}_{7}\left(118.6(2)^{\circ}\right)[20]$, but it appears from the literature dealing with non-protoned diphosphates that on average, the P-O-P angle for hydrated compounds ( $127^{\circ}$ for 16 occurences $)$ is slightly lower than for anhydrous ones $\left(133^{\circ}\right.$, for 63 occurrences, excluding angles of $180^{\circ}$ resulting from a positional disorder of diphosphates groups or highly anisotropic motion of $\mathrm{O}_{\mathrm{b}}$ ). Generally, a low angle is observed when the bridging oxygen atom is bonded to an external cation (ie, Na- $\mathrm{O}_{\mathrm{b}}=2.426(2) \AA$ in $\mathrm{Na}_{4} \mathrm{P}_{2} \mathrm{O}_{7}$ [21]) or, in the second case, when a water molecule is close enough (2.6 to $3.1 \AA$ ) to form an hydrogen bond with it. $\alpha$-TPDH appears as an ideal case for such a distortion, with two water molecules near $\mathrm{O}_{b}$ $\left(d \mathrm{O}_{\mathrm{w}}-\mathrm{O}_{\mathrm{b}}=2.93(3) \AA\right)$ and placed in such a manner that they can pull the bridging oxygen away from the $\mathrm{P}(2)-\mathrm{P}(2)$ axis (Figure 8). 


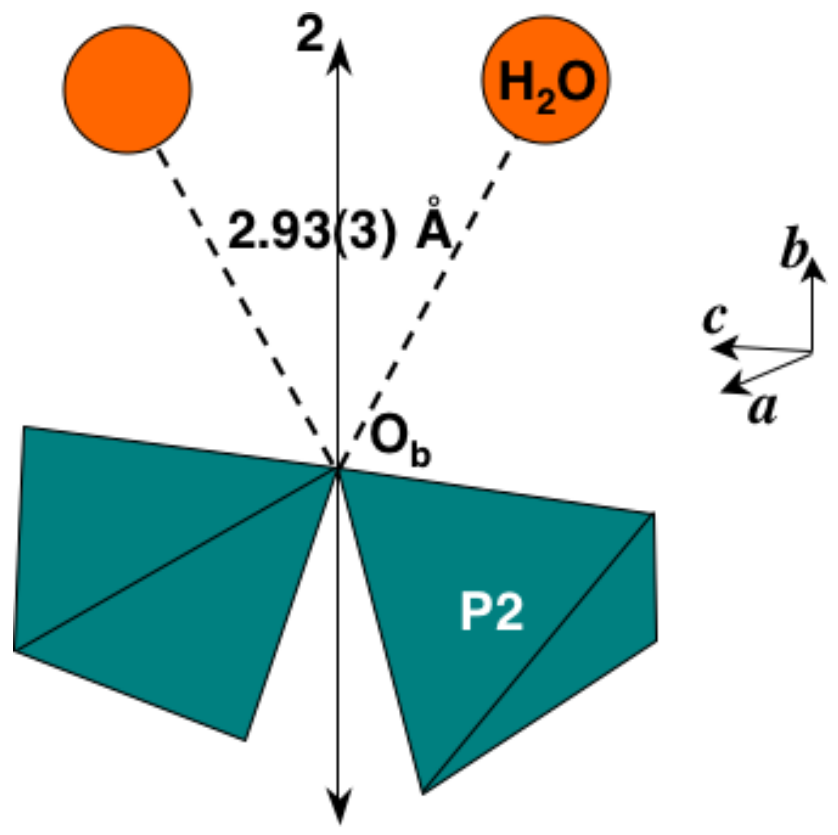

Fig. 8. The bending effect of the hydrogen bonds on the diphosphate unit of $\alpha$-TPDH.

\section{Discussion}

The $\left[\mathrm{Th}_{4}\left(\mathrm{PO}_{4}\right)_{4}\right]^{4+}$ slab remains remarkably unchanged between TPHPH, $\alpha-\mathrm{TPDH}$ and $\alpha-\mathrm{TPD}$, in spite of the evolution of the interslabs species. In the three forms, the thorium atom shares about 3.3 valence units with the slabs oxygens, accounting for the stability of this pseudo-monazite array. On the opposite, the network of Th bonds with $\mathrm{HPO}_{4}$ oxygens appears very weak, in agreement with the platelet habit of the TPHPH crystallites.

The water molecule in TPHPH and in $\alpha$-TPDH plays a significant structural role by completing the coordination polyhedron of half of the thorium atoms. Its absence explains the tendency of $\alpha$-TPD to re-hydrate promptly when left in air. The similar behavior of TPHP has probably the same origin. The $a$ parameter is only faintly sensitive to the presence of water, because the interslabs are templated by the bigger $\mathrm{HPO}_{4}$ or $\mathrm{P}_{2} \mathrm{O}_{7}$ units, however, the de-hydration leaves wide cavities, as shown for $\alpha$-TPD in Figure 9. 


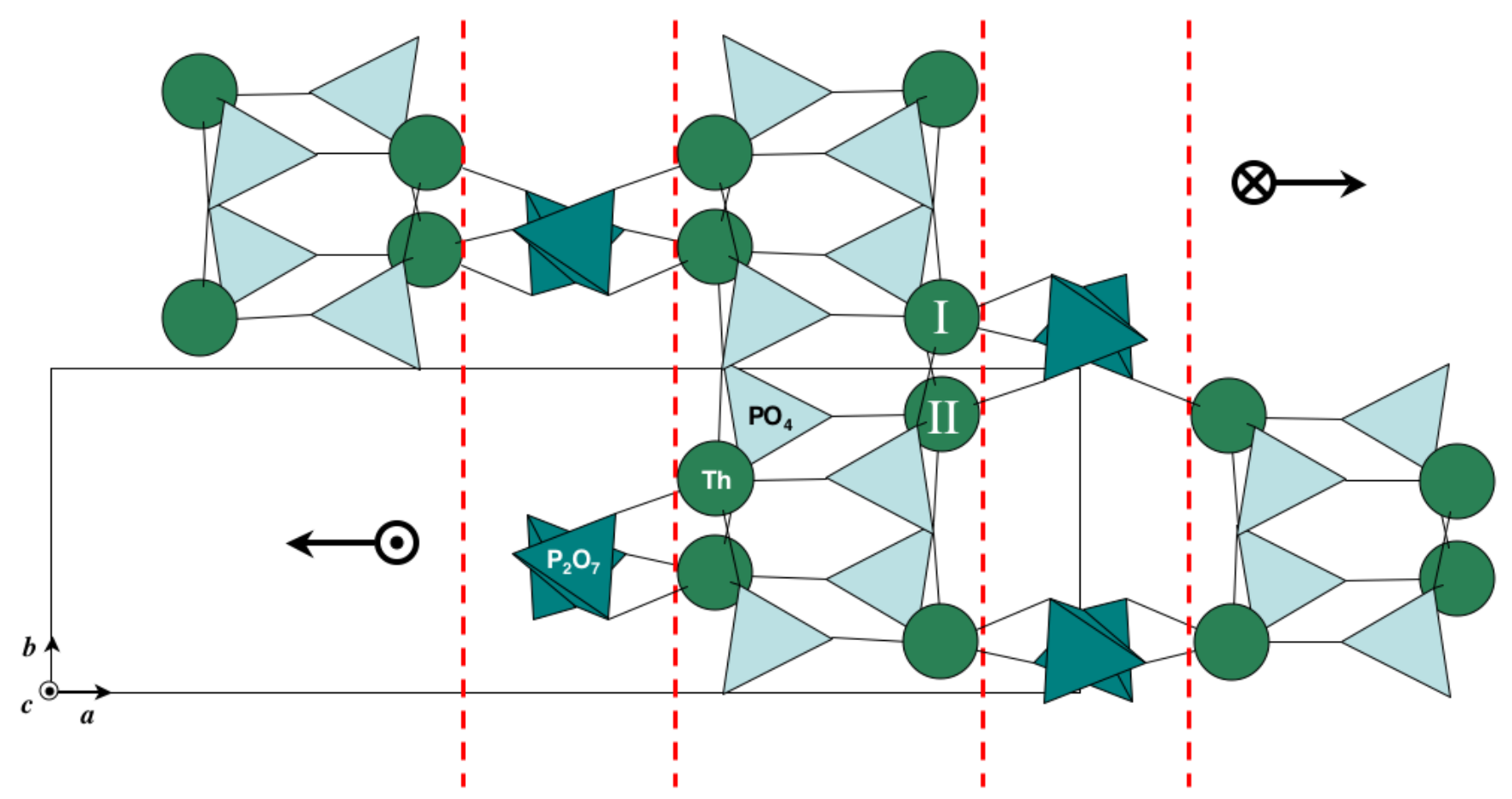

Fig. 9. (001) view of $\alpha$-TPD. The arrows feature the shearing leading to $\beta$-TPD.

The $\alpha$-TPD/ $\beta$-TPD transition near $950{ }^{\circ} \mathrm{C}$ is a break in the structural continuity that prevailed up to this temperature. A structural explanation of its mechanism can be proposed by comparing the (001) projections of the two forms (Figures 9 and 10). Let us observe, for example, the movements of two thorium atoms belonging to the same slab: in Figure 9, Th/I is located in the mirror plane at $z=3 / 4$ (upper level), Th/II at $z=1 / 4$ (lower level). After shifting parallel to the (010) plane at $y=1$, following the arrows, these atoms can be found again in Figure 10. Note that Th/I and Th/II, now at the same $z=$ 3/4 (upper) level, have become non-equivalent in the process. In a more general way, the transformation occurs via a $\pm(\boldsymbol{a} / 8$ - $\boldsymbol{c} / 4)$ alternate shearing, occuring in the (010) planes with integer $y$ 's of the $\alpha$-cell. The flat slabs of $\alpha$-TPD sustain an enormous deformation (see dashed lines) and the empty cavities of the interslabs vanish, thus explaining the $5 \%$ reduction of the volume per formula. The transverse shearing requires the breaking and reformation of some intra-slabs Th-O bonds, but the densification of the framework allows to form new inter-slabs bonds (asterisked in Figure 10). On the contrary, the $c$ parameter, corresponding to the thickness of two layers remains almost unchanged $(+0.5 \%)$. 


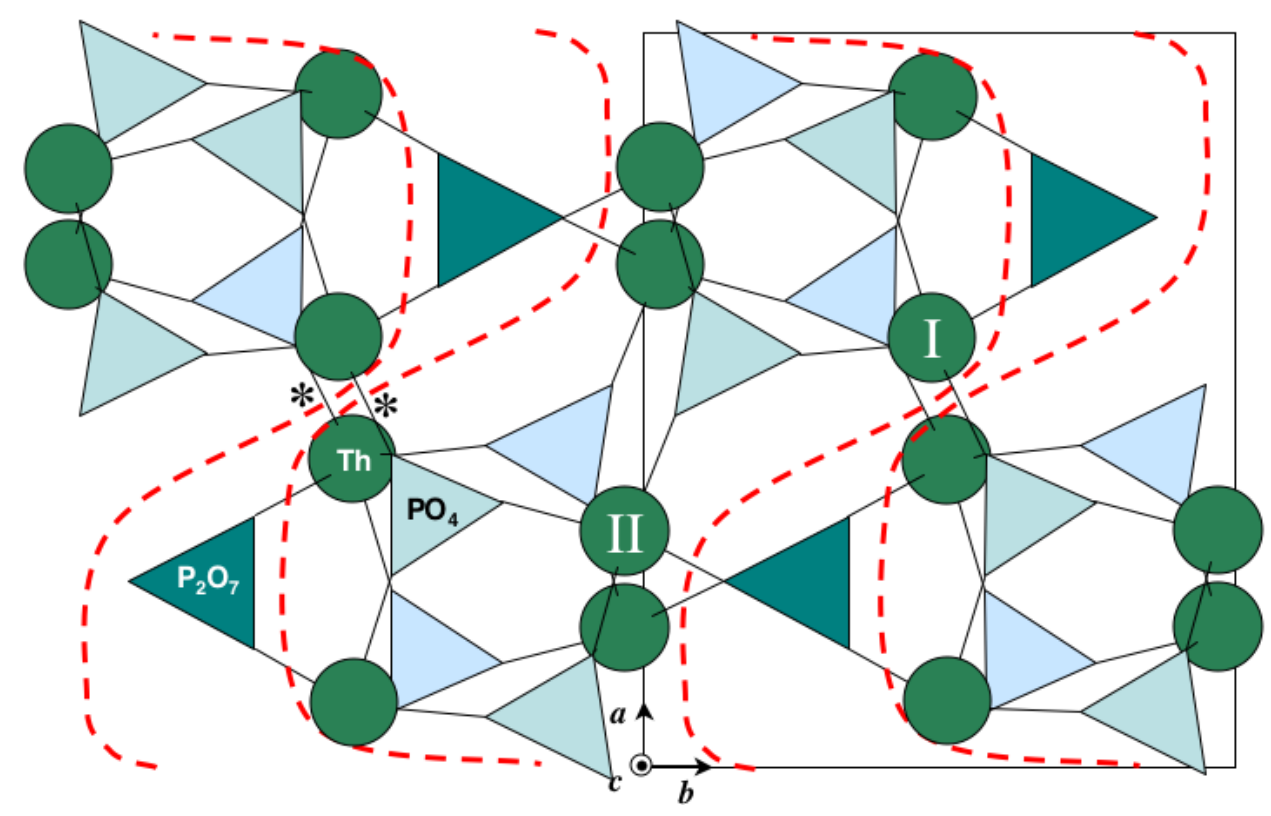

Fig. 10. (001) view of $\beta$-TPD, showing the same atoms as in Figure 9. Note the reduction of the interslabs cavities and the corrugated shape of the slabs, now linked by the asterisked bonds.

At last, the $\mathrm{P}_{2} \mathrm{O}_{7}$ units realign along the $c$-axis of $\beta$-TPD, but in the light of this study, their random array along the $\boldsymbol{c}$-directed $\mathrm{P}_{2} \mathrm{O}_{7}$ chains, observed by single-crystal XRD and NMR [10] appears as a remanence of the disorder of the interslabs species in TPHPH and $\alpha$-TPD.

Whereas $\alpha$-TPD is a $2 \mathrm{D}$ compound, $\beta$-TPD is nearly 3D and can be grown as regular-shaped crystals instead of platelets. However, the location of Th atoms in irregular polyhedra at the surface of the slabs allows to regard important substitutions for this cation, because variations of the ionic radius of the tetravalent cation can be absorbed by slight deformations of the framework. Indeed, the flexibility of the corrugated slabs has been evidenced in the frame of a dilatometric study [22].

The absence of cavities in $\beta$-TPD and the cumulated bond strengths of 4.1 and 4.3 around the thorium atoms explain why the ultimate form is immune from re-hydration, at variance with $\alpha$-TPD and TPHP. Furthermore, the collapse of the structure justifies the exothermal character of the transition: $\alpha-$ TPD, unstable in standard conditions because of its tendency to re-hydrate, becomes metastable at high temperature, until the thermal energy becomes sufficient to activate the first-order transition and stabilize the thorium atoms by forming inter-slabs bonds. In both cases, the necessity to complete the coordination polyhedron of Th by filling or reducing the cavities appears as a thermodynamic necessity. 
The other positive point resulting from the structure collapse is the compactness of the framework of the $\beta$-form, that offers a better resistance to the water penetration, in agreement with the excellent performance of this material in terms of leaching and solubility [3].

\section{Conclusion}

The present study allows now to understand how, starting from a soft and foliated precursor, $\beta$ TPD achieves its remarkable stability towards temperature, water and other aggressive media after a series of thermal evolutions affecting first the interslabs, then the slabs themselves through an irreversible and exothermal transition. These criteria are of considerable importance with regard to its applications as a host material for the long-term storage of actinides.

Acknowledgements. This work was supported by the French research group NOMADE (NOuveaux MAtériaux pour les DEchets). The authors are very grateful to Jean-Paul Souron (Université Paris VI, France) for the DTA/TGA experiments.

\section{References}

[1] J.-C. André, C.R. Acad. Sci. Paris IIA 333 (2001) 835.

[2] N. Dacheux, N. Clavier, A.-C. Robisson, O. Terra, F. Audubert, J.-E. Lartigue, C. Guy, C.R. Acad. Sci. Paris 7 (2004) 1141.

[3] A.-C. Thomas, N. Dacheux, P. Le Coustumer, V. Brandel, M. Genet, J. Nucl. Mater. 281 (2000) 91.

[4] A.-C. Thomas, N. Dacheux, V. Brandel, P. Le Coustumer, M. Genet, J. Nucl. Mater. 295 (2001) 249.

[5] A.-C. Robisson, N. Dacheux, J. Aupiais, J. Nucl. Mater. 2002, 306, 134.

[6] V. Brandel, N. Dacheux, M. Genet, Radiokhimiyia 43 (2001) 16.

[7] V. Brandel, N. Dacheux, E. Pichot, M. Genet, J. Emery, J.-Y. Buzare, R. Podor, Chem. Mater. 10 (1998) 345. 
[8] V. Brandel, N. Dacheux, M. Genet, in "Procédés de préparation d'un produit à base de phosphate de thorium et/ou d'uranium (IV) en vue de la décontamination d'effluents radioactifs“, Patent 03739522.5-2111-FR0300426, 2003.

[9] V. Brandel, N. Clavier, N. Dacheux, J. Emery, M. Genet, G. Wallez, M. Quarton, Materials Research Bulletin 40 (2005) 2225.

[10] P. Bénard, V. Brandel, N. Dacheux, S. Jaulmes, S. Launay, C. Lindecker, M. Genet, D. Louër, M. Quarton, Chem. Mater. 8 (1996) 181.

[11] M. A. Salvado, P. Pertierra, A. I. Bortun, C. Trobajo, J. R. Garcia, Inorg. Chem. 44 (2005) 3512.

[12] J. Rodriguez-Carvajal, FULLPROF.2k: Rietveld, profile matching and integrated intensity refinement of X-ray and neutron data, V 1.9c, Laboratoire Léon Brillouin, CEA, Saclay, France, 2001.

[13] G. M. Sheldrick, SHELX-97: A Program for Crystal Structure Determination, Göttingen, Germany, 1997.

[14] J. Gonzalez-Platas, J. Rodriguez-Carvajal: GFOURIER: Fourier maps calculation program, V 3.20, Universidad de La Laguna, Tenerife, Spain and Laboratoire Léon Brillouin, CEA, Saclay, France, 2003.

[15] Lis, T. Acta Cryst. C 50 (1994) 484.

[16] N. E. Brese, M. O’Keeffe, Acta Cryst. B 47 (1991) 192.

[17] M. Nazaraly, G. Wallez, C. Chanéac, E. Tronc, F. Ribot, M. Quarton, J.-P. Jolivet, Angew. Chem. 44 (2005) 5691.

[18] E. Pichot, J. Emery, E. Quarton, N. Dacheux, V. Brandel, M. Genet, Materials Research Bulletin 36 (2001) 1347.

[19] A. Rulmont, R. Cahay, M. Liègeois-Duyckaerts, P. Tarte, Eur. J. Solid State Inorg. Chem. 28 (1991) 207.

[20] F. Erragh, A. Boukhari, F. Abraham, B. Elouadi, J. Solid State Chem. 120 (1995) 23.

[21] K. Y. Leung, C. Calvo, Canadian J. of Chem. 50 (1972) 2519.

[22] S. Launay, G. Wallez, M. Quarton, Chem. Mater. 13 (2001) 2833. 
Supporting Information Available: The cif files on the crystal structures are available via the Internet from the Fachinformationszentrum Karlsruhe, 76344 Eggenstein-Leopoldshafen, Germany (e-mail: crysdata@fiz-karlsruhe.de, fax: (+49) 7247-808-666) on quoting the depository CSD-numbers 415919 ( $\alpha$-TPDH), 415920 ( $\alpha$-TPD), 415921 (TPHPH).

\section{Graphic abstract}

The 2D structure of the TPHPH precursor, that sustains first the $\mathrm{HPO}_{4}$ condensation and dehydration in the interslabs, then a shearing of the slabs leading to stable $\beta$-TPD, a 3D framework suitable for longterm storage of actinide elements.

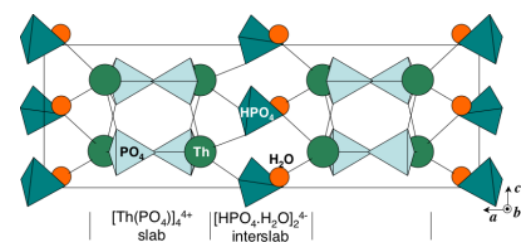

